\title{
Production of Bacillibactin Siderophore from Soil Bacteria, Bacillus subtilis: A Bioinoculant Enhances Plant Growth in Arachis hypogaea L. Through Elevated Uptake of Nutrients
}

\author{
Lalitha $S^{1^{*}}$ and Nithyapriya $S^{1}$ \\ $1^{*}$ Department of Botany, Periyar University, Salem 636011.Tamil Nadu, India, \\ ${ }^{1}$ Department of Botany, Padmavani Arts and Science Collage for women, Salem 636011.Tamil Nadu, India. \\ * Corresponding author Email-lara9k@gmail.com
}

\begin{abstract}
Siderophores are iron chelator low molecular weight secondary metabolite produced by microorganisms found in limited iron environment. In this study, a bacterium capable of secreting siderophores was isolated from the iron deficiency rhizosphere agriculture soil from Salem district, Tamil Nadu, India. The isolate was identified as Bacillus subtilis(LSBS2) based on biochemical characteristics and 16S rRNA gene sequences analysis. The siderophores production ability of the strain was evaluated qualitatively and quantitatively through Chrome Azural S assay. The TLC analysis of the LSBS2extract developed brown colour spots indicating catacholate type of siderosphore of isolate had the ability to produce $20 \mathrm{mg} \mathrm{L}^{-1}$ of siderophores in liquid medium. Further, the siderophores was partially purified and identified as bacillibactin type using HPLC, FTIR and the bacillibactin structure was confirmed by 2D-NMR analysis. Furthermore, a field experiment was conducted with Arachis hypogaea to assess the inoculation effect of LSBS2 on plant growth and other physico-chemical parameters. Inoculation of LSBS2 increased plant biomass, pigment content, nutrients, Iron content and oil content than the uninoculated control. The present result suggested that the occurrence of bacillibactin type siderophores in strain LSBS2 play a key role in iron chelation and favors the healthy growth of Sesamum indicum. Therefore, the strain LSBS2 could be exploited as a potential bioinoculant for stimulating peanut plant immunity.
\end{abstract}

Keywords: Siderophore, Phosphate Solubilization, bioinoculant, Sesamum indicum, Bacillibactin

\section{INTRODUCTION}

Siderophore producing Plant Growth Promoting Rhizobacteria (PGPR) helps in the iron requirement of plants via inflicting its solubilization and chelation from organic or inorganic complexes present in soil and additionally assist in the safety of plant-pathogen due to the fact of iron-deficient stipulations between the plant and pathogen [1].

Siderophores produced by PGPR to protect plants from phytopathogens [2] furthermore, the iron need of plants by causing solubilization and chelation from natural or inorganic edifices present in the soil. Phytopathogens have repressed the rhizosphere of siderophore creating PGPR on account of iron starvation or because of forceful rejection in ironlacking conditions [3].

Bacillus species have the ability to produce diverse classes of antimicrobial secondary metabolites, enzymes, and rare carotenoids. Bacillus has been documented under diversified fields and horticultural crops. A good number of plants associated with Bacilli have been commercialized as bioinoculants for protection of plants growth [4].
Bacillus subtilis produces the catecholate siderophore 2,3- dihydroxybenzoate (DHB) and 2,3dihydroxybenzyl glycine (DHBG). Itoic acid (DHBG) is the glycine conjugate of 2,3- dihydroxybenzoate (DHB). These DHB and DHBG act as precursor for the production of catecholate siderophore bacillibactin, the cyclic trilactone of 2,3dihydroxybenzoyl [5].

Investigation of the siderophore creation by Bacillus subtilis delivered the catecholic siderophore 2,3-dihydroxybenzoate-glycine-threonine trimeric ester bacillibactin, and that siderophore efficiency was inhibited by iron.

Bacillibactin is the model triscatetholate siderophore first isolated from gram-positive microbes. It is a trisbidentate chelator based on cyclic trilactone framework with 2,3, a dihydroxybenzoic useful gathering with the expansion of a glycine spacer, and methylation of the trilactone ring possessing to the threonine fused in bacillibactin. It is important for the most elevated known liking for iron $\mathrm{Fe} 3+$ of normal siderophores and bacillibactin has 
been expressed as the predominant extracellular ferric iron scrounger of Bacillus subtilis under iron limitation.

PGPR biofertilizers for high yielding crop production and soil fertility. Bacillus biofertilizer are the most prominent and facilitate the effective formulation of biofertilizer, leading to sustainable agriculture [6]. PGPR typically used as biostimulation, biocontrol and biofertilizer the plant growth. [7]

Arachis hypogaea L. belongs to the family Fabaceae it is popularly recognized as poor man's nut has been accepted by Indian as a vegetable oil seed crop and has occupied the first place amongst oil seed plants grown in the country. Worldwide, peanut cultivation is 26.4 million hectares with a whole yearly manufacturing of 39.46 million metric lots.

Therefore, the present study was undertaken (i) Identification of Bacillus subtilis for siderophore production, (ii) purification and characterization of siderophore, (iii) Efficacy of bacillibactin siderophore bioinoculant and growth of plant in Arachis hypogaea

\section{MATERIALS AND METHODS}

\subsection{Culturing of microbes}

Rhizosphere soils were obtained from different crops including, Zeamays, Arachis hypogaea plant rhizosphere region in $\left(11.8384^{\circ} \mathrm{N}, 78.0545^{\circ} \mathrm{E}\right)$ Salem district Tamil Nadu, India. The rhizospheric bacteria were isolated from serial dilution technique.

\subsection{Biochemical characterization}

The potent isolates were further characterized based on their staining characteristics and further investigated in terms of biochemical properties like indole, catalase, urease, citrate, ammonia, and nitrate producing abilities, which helped in identifying the bacteria up to genus level [8]

\subsection{Molecular Identification of $16 S$ rRNA Gene Sequencing}

Molecular characterization of the potent PGPR isolates was done by $16 \mathrm{~S}$ rRNA gene amplified by polymerase chain reaction (Biorad system, USA). The purified PCR products were sequenced and the sequence assembly was carried out using Finch TV version 1.4.0 (www.geospiza.com) and homology of the sequence was confirmes using BLASTN program. The obtained sequence information can be accessed in the NCBI (National Centerfor Biotechnology Information) [9].

\subsection{Screening for Siderophore production}

Bacteria isolate was cultured in iron-lacking Chrome azurol ' $\mathrm{S}$ ' agar (CAS) medium [10]and incubated at $28{ }^{\circ} \mathrm{C}$ for $72 \mathrm{~h}$, plates were monitored for the formation of halo-orange zones.

\subsection{Siderophore assay}

Assessment of siderophores was performed using a reaction mixture containing $1 \mathrm{~mL}$ of CAS reagent and
$1 \mathrm{~mL}$ of cell free supernatant and was measured at $630 \mathrm{~nm}$. The CAS reagent and Non-inoculated broth served as control or reference. The amount of siderophore units (SU) was calculated based on the formula as follows:

$\% \mathrm{SU}=\mathrm{As}-\mathrm{Ar} / \mathrm{Ar} \times 100$.

As $=$ absorbance of the test sample at $630 \mathrm{~nm}$

$\mathrm{Ar}=$ absorbance of control or reference at $630 \mathrm{~nm}$

\subsection{Type determination of siderophore production}

Arnow's assay consisting solution containing $1 \mathrm{~mL}$ of supernantant, $1 \mathrm{~mL}$ of $\mathrm{HCl}(0.5 \mathrm{M}), \mathrm{NaOH}$ $(1 \mathrm{M})$ and $1 \mathrm{~mL}$ of Nitrite-molybdate reagent and observed for for colour change. The formation of red coloured indicates the presence of catecholate type of siderophore [11].

\subsection{Purification of siderophore}

Siderophore fractional purification was performed using amberlite IR120 $(\mathrm{Na}+)$ ion exchange chromatography. Bacterial cells capable of secreting siderophores were centrifuged at $12000 \mathrm{rpm}$ for $7 \mathrm{~min}$ and the resultant supernatant was harvested as crude siderophores. The crude siderophore supernatant was allowed to run into an ion exchange chromatographic column. The siderophore was finally harvested with $60 \%$ of methanol and used for further studies.

\subsubsection{TLC of purified siderophore}

Crude siderophore supernatant was spotted drop by drop on TLC plates (Merck, thickness 0.25 $\mathrm{mm}$ of Silica gel G) using mobile phase isopropanol:acetic acid: $\mathrm{ddH}_{2} \mathrm{O} \quad(12: 3: 5)$ fully developed TLC plates were spraying with $25 \mathrm{~mL}$ of $0.1 \mathrm{M}$ of $\mathrm{FeCl}_{3}$ in $0.1 \mathrm{~N} \mathrm{HCl}$ reagents that are specific to detect the presence of types of siderophores.

\subsubsection{FTIR analysis of purified siderophore}

Extract containing the purified siderophore was completely dried and processed to FTIR analysis (PerkinElmer spectrometer) using absorption mode of 4000- $400 \mathrm{~cm}^{-1}$ range.. The IR spectrum wavelengths were determined based on its functional groups.

\subsubsection{HPLC analysis of purified siderophores}

The purified siderophores was subjected to HPLC (Shimadzu, Tokyo, Japan) using the stationary phase pinnacle II C18 reverse phase column $(5 \mu \mathrm{M}$ integrated pre column, $250 \times 4.6 \mathrm{~mm}$ ) and methanol:water $(8: 2 \mathrm{v} / \mathrm{v})$ used as mobile phase with 1 $\mathrm{ml} \mathrm{min}^{-1}$ flow rate of $25{ }^{\circ} \mathrm{C}$ at $400 \mathrm{~nm}$. The preparatory separation of siderophore was done using same mobile phase with $7: 3 \mathrm{v} / \mathrm{v}$.

\subsubsection{Nuclear Magnetic Resonance (NMR) spectroscopy}

The NMR spectrum of the purified siderophores was recorded using (Brucker AM-500, $500 \mathrm{MHz}$, Switzerland) spectroscopy using standard 
compound, $\mathrm{D}_{2} \mathrm{O}$ solvent as an internal signal reference and chemical shift was recorded in ppm. The test compound was also compared with the peaks of the standard target compound by NMR.

\subsection{Physico-chemical analysis of soil test}

The soil samples were collected from control and treated plants before sowing and after harvesting and label separately. This physico-chemical property such as $\mathrm{pH}$ and Electrical Conductivity, nitrogen, phosphorus, potassium, copper, zinc, iron and manganese were estimated

\subsection{Field experiments}

The field experiment was conducted in a farmer's field Salem district, Tamil Nadu, India respectively to evaluate the efficacy of Bacillus and control. The susceptible Arachis hypogaea seeds were obtained from the Agriculture department, Seelanaickenpatti, Salem district, Tamil Nadu, India. Seeds were treated with the talc formulation of Pseudomonas and Bacillus. The field trial was conducted in a randomized complete block design area of $5 \times 3 \mathrm{~m}^{2}$ and seven Arachis hypogaea (approximately 225 holes three seed per hole). Rowto-row and plant-to-plant spacing were maintained at $30 \mathrm{~cm}$ and $20 \mathrm{~cm}$, respectively. During the whole growth period no agrochemicals and additional artificial watering were applied to the farmland. Plants were harvested Arachis hypogaea at 90 DAI compared to inoculants treated plants and noninoculants plants.

\subsubsection{Field data analysis}

Three plants were taken from the each plot randomly. They were recorded in shoot length, root length, fresh weight, dry weight, when compared to bio inoculation and uninoculated plants.

\subsubsection{Nitrogenase activity of root nodules (Arachis hypogaea) \\ Nodulated roots were cut and slowly to remove the attached soil particles. Samples were assayed by [12]. The results expressed in nanomoles of ethylene formed.}

\subsubsection{Leghaemoglobin content of root nodules (Arachis hypogaea) \\ About 50 to $100 \mathrm{mg}$ of root nodules were} collected and crushed in 9 volumes of Drabkins solutions in a microphage tube. The tubes were centrifuged at $12000 \mathrm{rpm}$ for $15 \mathrm{~min}$. Leghaemoglobin content described by [13]

\subsubsection{Yield parameters}

Arachis hypogaea pods were removed from the plant, counted the number of pods per plant and weight of pods were recorded (wt.pods/plant/g).Number of pods was expressed by the (Number. pods /plant). The seeds were disinterested from the pod and the number of seeds were counted per plant and they were expressed in (Number. seed/plant).

\subsubsection{Estimation of photosynthetic pigments $(\mathrm{mg} / \mathrm{g})$ \\ Total chlorophyll and carotenoids contents} were extracted from leaves and estimated according to the method of Arnon [14] and the carotenoids content was estimated by according to the method of [15]. Chlorophyll content was calculated by using the formula of Arnon [16].

\subsubsection{Nutrients analysis of seed}

Arachis hypogaea seeds were harvested from bioinoculant treated and untreated control plants seeds were cooled at room temperature. The dried seed samples were grinded finely and digested with $25 \mathrm{ml}$ of concentrated sulphuric acid. The digested residue were transferred to a volumetric flask and adjusted to $50 \mathrm{ml}$ using deionized water. Analysed for total fat, carbohydrate, protein, energy, calcium and iron content after diluting the concentrated digests with deionized water, the concentration was recorded using atomic absorption spectrophotometer.

\subsubsection{Estimation of total seed oil content}

Hundred gram of dried seeds harvested from each treatment were used for the determination of total oil content. Briefly, seeds were extracted using chloroform and the extracted powdered samples were subjected to Sokule device until complete evaporation of the chloroform.

$\%$ Ether extract $=(($ weight of flask + extract - tare weight of flask) / weight of sample) $\mathrm{x} 100$ (Determination of mineral content in Indian spices).

\subsection{Statistical analysis}

Data were represented as mean \pm standard error (SE) obtained from three replicates performed in duplicates. Statistical analysis was performed using SPSS 21.0 version. The significant differences in the means were analysed based on Tukey'smultiple comparison test $(\mathrm{P}<0.05)$

\section{RESULTS}

\subsection{Isolation of Bacillus subtilis (LSBS2)}

LSBS2 was isolated from the iron deficiency rhizosphere agriculture soil from Salem district, Tamil Nadu, India.The bacterial isolate LSBS2 was cells would appear purple in colour because they have a thick layer of cell wall are present this is confirms gram positive bacteria. The detail results of the biochemical characterization of the bacterial isolate are given in (Table 1).

\section{2. $16 S$ r RNA genes sequencing}

Biochemical test followed by16S $\mathrm{r}$ RNA gene sequencing analysis using BLAST search of 
NCBI. The obtained 16s RNA gene sequence revealed 96.3 to $97.2 \%$ similarity with the sequence of Bacillus subtilis available in the GenBank. (Fig. 1). The newly isolated siderophore producing Bacillus subtilis isolate (LSBS2) with accession number MK4832621was deposited in the GenBank.

Table 1. Biochemical identification of bacterial isolation

\begin{tabular}{|c|l|c|}
\hline NO & \multicolumn{1}{|c|}{ Test } & LSBS2 \\
\hline 1 & Gram staining & + \\
\hline 2 & Indole production & + \\
\hline 3 & Methyl Red & + \\
\hline 4 & Voges-proskaur & + \\
\hline 5 & Citrate utilization & + \\
\hline 6 & Starch hydrolysis test & + \\
\hline & Extra cellular enzymes activity & - \\
\hline 1 & Catalase activity & + \\
\hline 2 & Oxidase production & + \\
\hline 3 & Urea's activity & \\
\hline
\end{tabular}

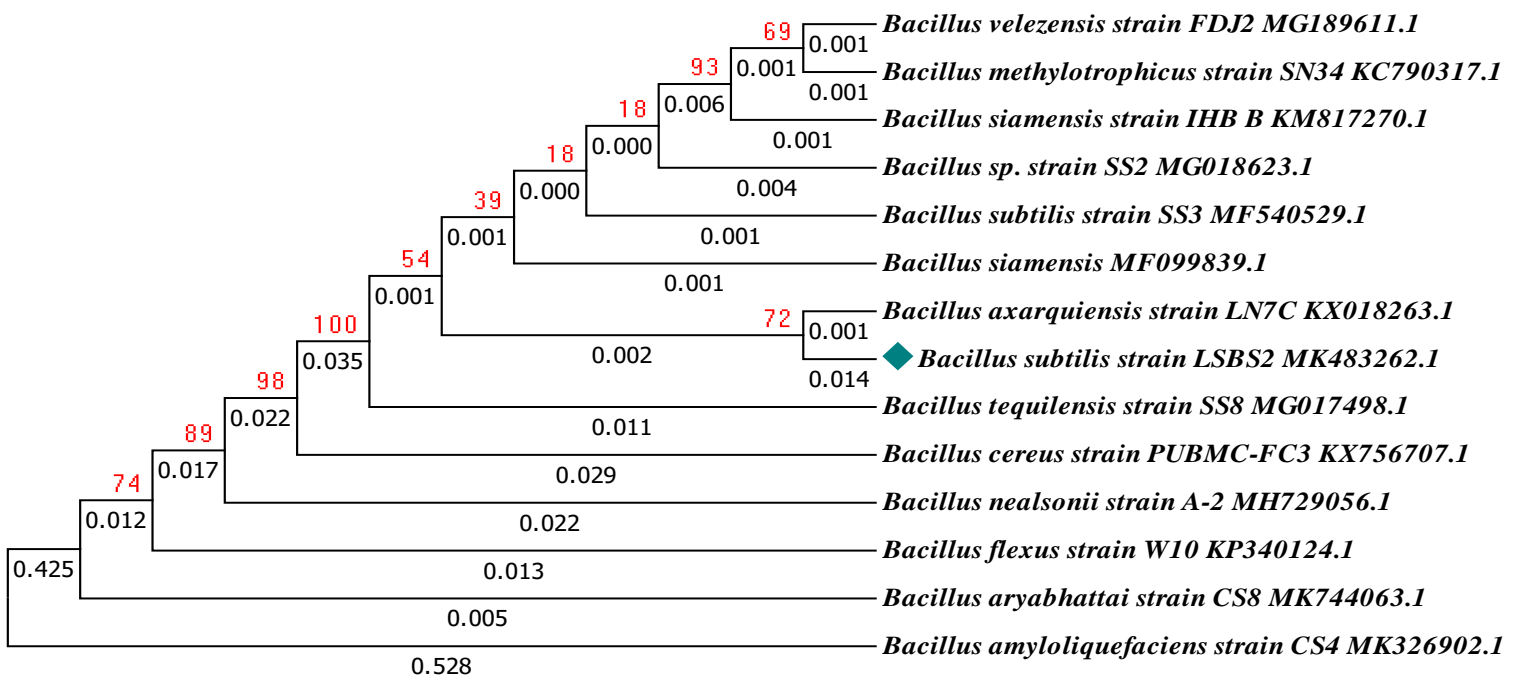

Figure 1 Phylogenetic tree on Bacillus subtilis 16S r RNA gene sequence. 


\subsection{Screening for Siderophore production}

In CAS assay LSBS2 showed positive reaction (orange colour zone) for siderophore production. The strain LNPF1 produced maximum of $10 \mathrm{~mm}$ sized orange colour zone in CAS plate (Fig. 2).

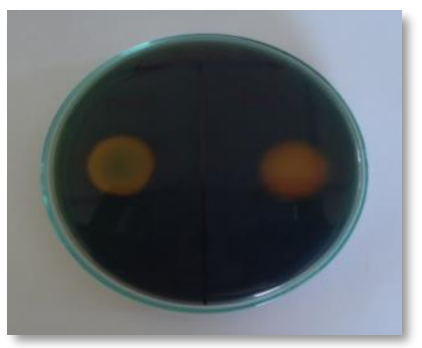

Figure 2. Formation of clear orange colour zone in response to siderophore production on CAS medium.

\subsection{Type determination of siderophore}

Arnow's assay was used to confirm the catecholate type of siderophore . $0.5 \mathrm{~N}$ hydrochloric acid, $1 \mathrm{ml}$ of nitrite molybdate reagent and $1 \mathrm{ml}$ of $1 \mathrm{~N}$ sodium hydroxide solution were added. The formation of a red coloured solution was considered as an indication of the presence of catecholate type of siderophore LSBS2 was confirmed the catecholate type of siderophore. Each catecholate group provides two oxygen atoms for chelation with iron.

\subsection{Thin layer chromatography of purified siderophore}

The siderophore produced by crude Bacillus subtilis(LSBS2) extract upon loaded on the TLC showed a red colour spot when sprayed with $0.1 \mathrm{M}$ $\mathrm{FeCl}_{3}$ in $0.1 \mathrm{~N} \mathrm{HCl}$ reagent. The red colour spots developed reveals the presence of catecholate type of siderosphore in the tested extract of LSBS2 isolate.

\subsection{Infra Red (IR) spectroscopy analysis of purified siderophore}

The partial purification of siderophore resulted a yield of $20 \mathrm{mg} \mathrm{lit}^{-1}$. Further, FTIR spectrum of LSBS2 shows the adsorption bands at 3445, 2951, 1652, 1455 and $1143 \mathrm{~cm}^{1}$ respectively, which indicates the presence of $(-\mathrm{OH})$, aromatic $(-\mathrm{CH}),(-$ $\mathrm{C}=\mathrm{O}),\left(-\mathrm{CH}_{2}\right)$ and $(\mathrm{C}-\mathrm{O}-\mathrm{C})$ linkage. These functional groups are present in catecholate type of siderophore. So that the purification of siderophore production in FTIR analysis conformed to catecholate type are present in LSBS2 that are specific to compound 2,3 dihydroxybenzoic acid . (Fig. 3).

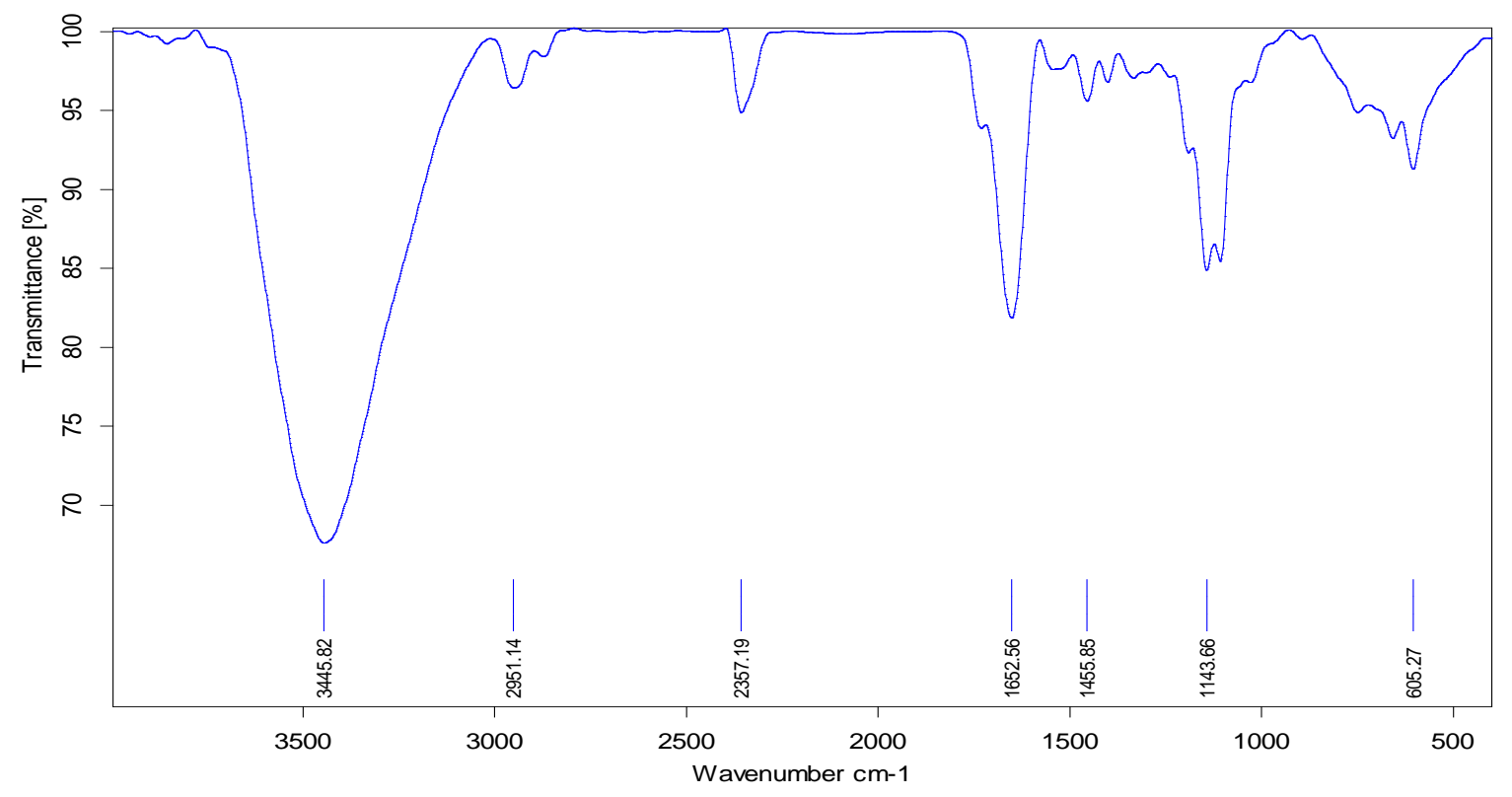

Figure 3. FTIR analysis of functional bands associated with catacholate type siderophore

\subsection{Determination of catecholate type of siderophore using HPLC}

The Confirmation of Purified siderophore were done by HPLC analysis using mixture of methanol: water $(80: 20 \mathrm{~V} / \mathrm{V})$ as a solvent system. In HPLC analysis the peaks appeared at retention time
$1.621 \mathrm{~min}, 2.188 \mathrm{~min}, 2.473 \mathrm{~min}$. The peaks appeared at 1-0.767 $\mathrm{min}, 2-2.033 \mathrm{~min}$, using was used as a standard. From these results it is clearly reveals that the presence of purified 2-3 dihydroxy benzoic acid siderophore in the sample (Fig. 4). 


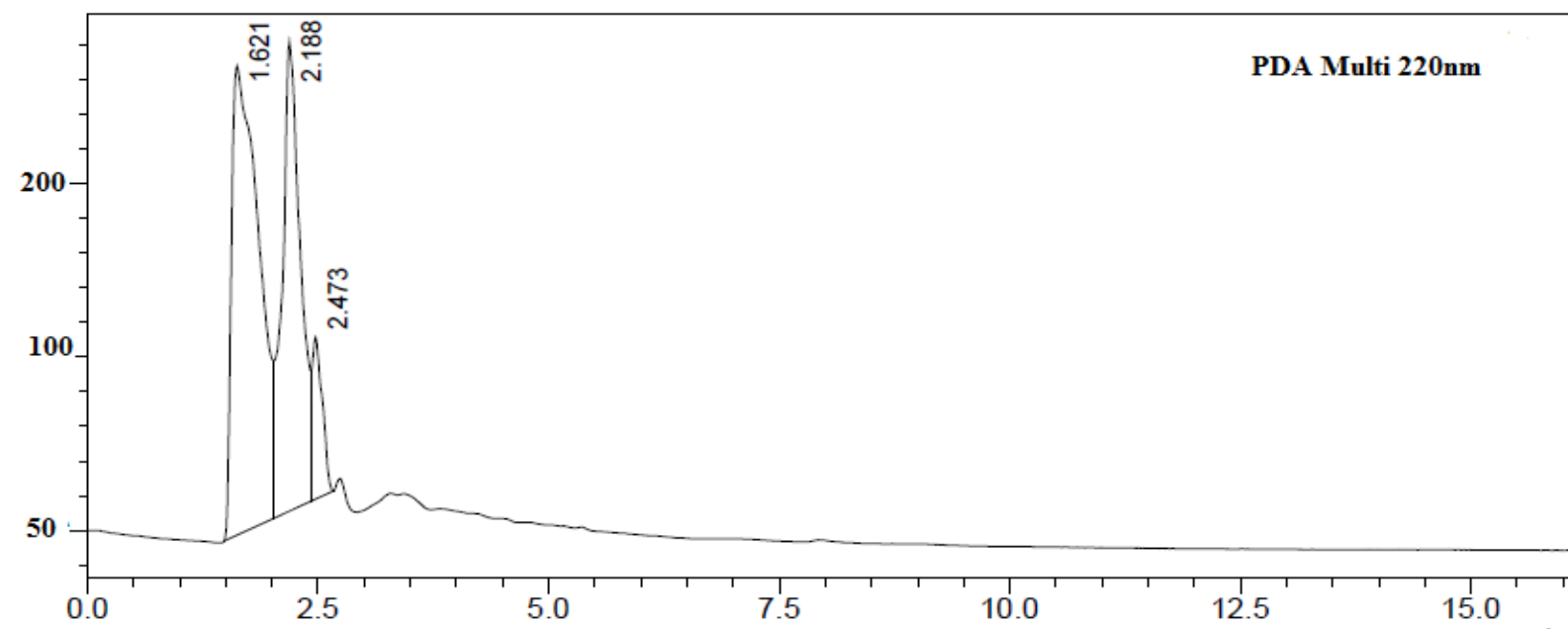

Figure 4 HPLC-analysis of purified catecholate type siderophore siderophore showing resemblance with the standard 2-3 dihydroxy benzoic acid siderophore in the sample

3.8 Structural characterization of Bacillibactin siderophore by NMR

In ${ }^{1} \mathrm{H}$ NMR aliphatic protons appeared at $1-4$ ppm aromatic protons appeared at 6-8 ppm respectively (Fig.5). In ${ }^{13} \mathrm{C}$ NMR 129.80 and 128.54 ppm which shows the presence of aromatic carbons which also confirms the presence of aliphatic carbons including $\mathrm{NHCOCH}_{2}$ linkage. (Fig.5.1) Overall, the accumulated peak values determines the chemical shifts as noticed from the 2D-NMR confirms the presence of catecholate type of siderophore in tested compound (LSBS2). Furthermore, the chemical hydrolysis in the 2D_NMR is considered as the most authentic evidence for the bacillibactin structure, an chelation of ferric iron which is a catecholate type of siderophore. Produced by the isolated Bacillus subtilis LSBS2.

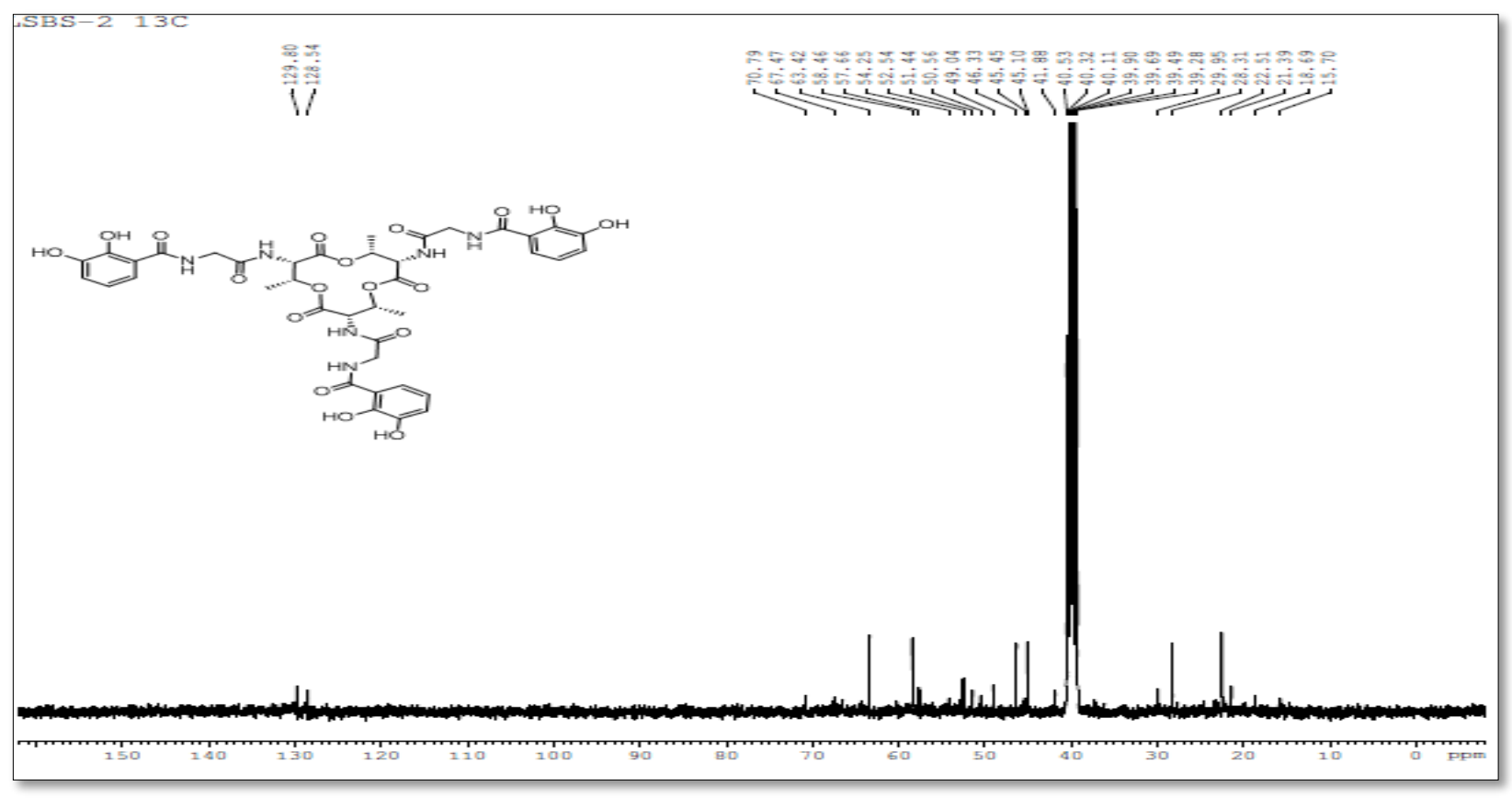

Figure 5. ${ }^{13} \mathrm{C}$ NMR analysis of purification of siderophore LSBS2 


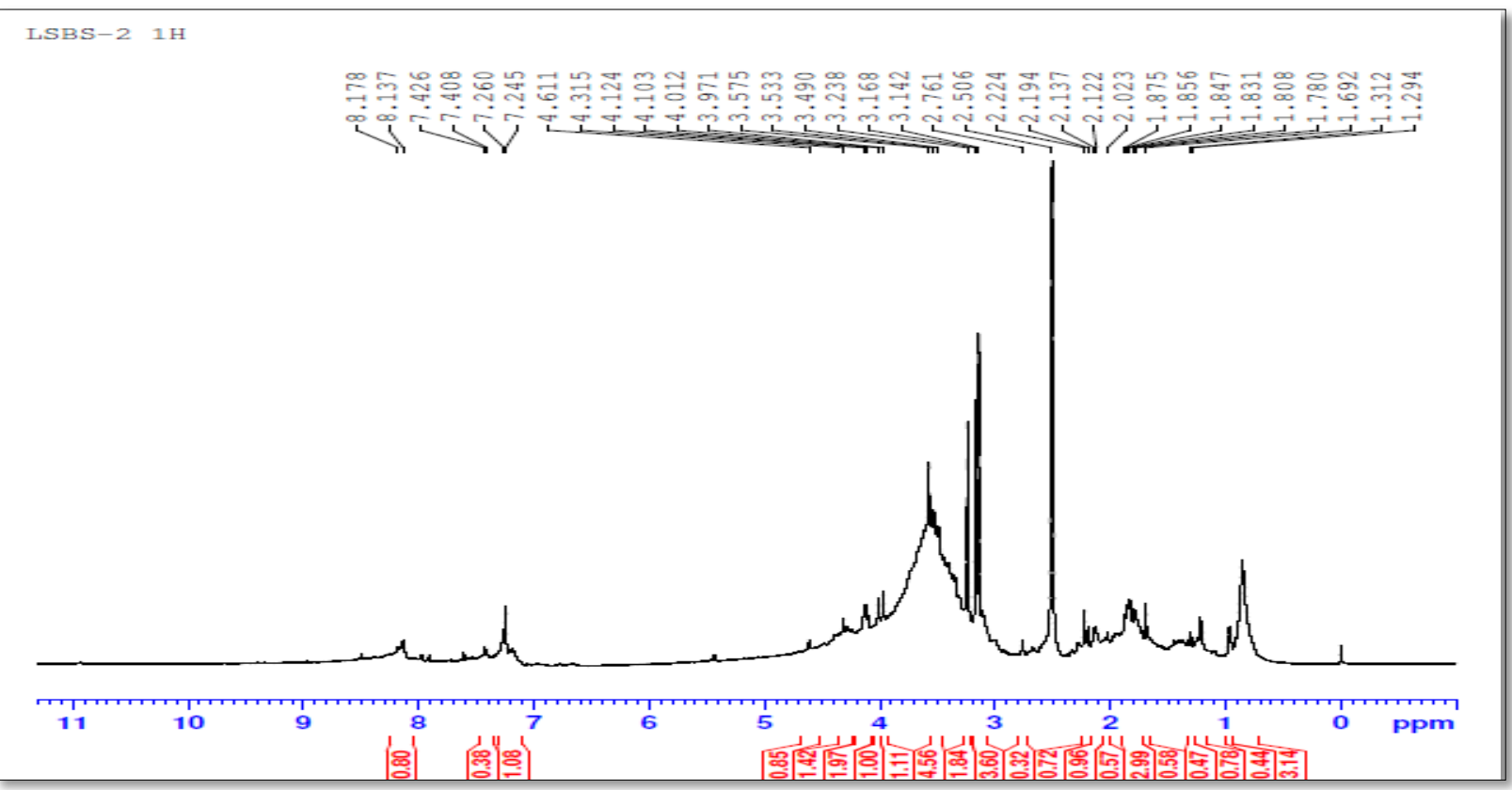

Figure 5.1. ${ }^{1} \mathrm{H}$ NMR analysis of purification of siderophore LSBS2

3.9 Post harvest studies on Arachis hypogaea (90DAI)

In field experiment the highest yield parameter were recorded in inoculation of Bacillus subtilis (Fig 6)significantly increase in shoot length, root length, the maximum was recorded in LSBS2 inoculated plants when compared to uninoculated control plants. Plant fresh weight significantly increased in LSBS2 (12.58g). Dry weight also increased in LSBS2 $(5.89 \mathrm{~g})$ showed significant increase when compared to uninoculated control plant
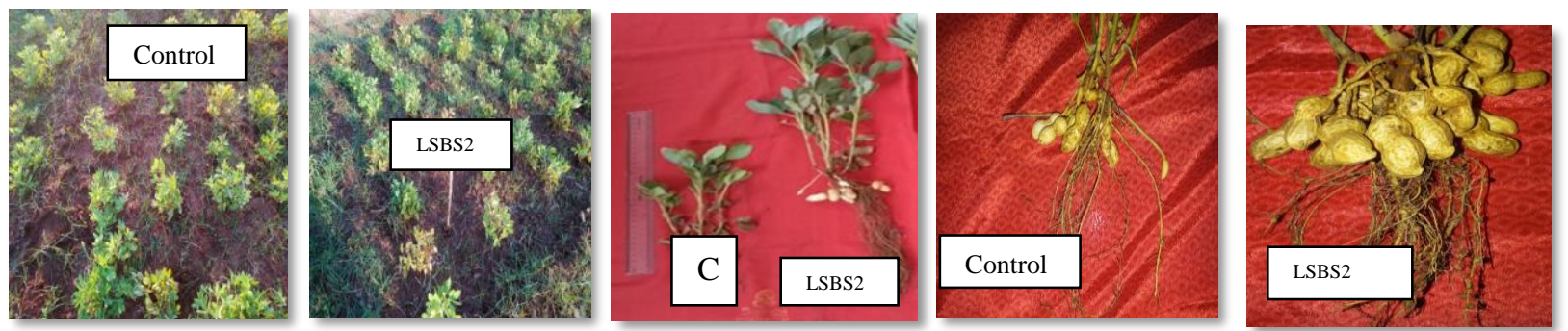

Figure 6 Bioinoculatant efficacy on plant growth parameters under field conditions

Total chlorophyll content significantly increased in leaf inoculation of LSBS2 $(1.01 \mathrm{mg} / \mathrm{g})$ and Carotenoids content $(0.03 \mathrm{mg} / \mathrm{g})$ when compared with control plants. The plant nitrogen content was assessed by increase in nitrogen accumulation, which was well pronounced in LSBS2 $(21.06 \pm 0.64 \mathrm{mg} \mathrm{N} / \mathrm{g}$ dry plant) when compared to control plants (Tables 3 )

The highest number of root nodules were observed in LSBS2 (38.0 \pm 2.64$)$ inoculated plants than in uninoculated plants $(23.33 \pm 1.52)$. Fresh weight and dry weight of root nodules showed significantly increase in LSBS2 and uninoculated control plants (Table 4).

Nodule nitrogenase activity was more in LSBS2 (14.80 $\pm 0.61 \mathrm{n}$ moles $\mathrm{C}_{2} \mathrm{H}_{4}$ formed / h / $\mathrm{g}$ fresh nodules). Leghemoglobin assay absorbance value of $540 \mathrm{~nm}$ were identified as Arachis hypogaea L. high concentration in inoculation of LSBS2 $(1.46 \mathrm{mg} / \mathrm{g})$ comparable to that un-inoculated plants $(1.2 \mathrm{mg} / \mathrm{g})$ (Tables 5)

Number of pods significantly increased in LSBS2 $(18.67 \pm 0.58)$ when compared to uninoculated plant (6.33 \pm 0.58$)$. Weight of pods per plant was also increased in LSBS2 $(12.57 \pm 0.20)$ inoculated plants than in uninoculated plants.100 seed weight/g was highest in LSBS2 (6.33g) inoculated plants than in control plant. Table 6)

Arachis hypogaea L plants when treated with bioinoculant showed significant increase in the nutrient content in dual inoculation of LSBS2 protein $(17.43 \%)$, carbohydrate $(21.50 \%)$, fat $(46.31 \%)$, fiber $(13.73 \%)$, iron $(6.36 \mathrm{mg} / \mathrm{g})$, calcium $(16.04 \mathrm{mg} / \mathrm{g})$, and energy $(563 \mathrm{Kcal})$ when compared to that control plants. Analysis of total seed oil content, the increase in percentage of oil content in seeds harvested from bioinoculant-treated plants with $49.66 \%$ to that of 
seeds obtained from un-inoculated plants which recorded only $38.36 \%$ of oil content. (Table 7).

Table 2. Physical characteristic of post-harvest studies Arachis hypogaea L. (90 DAI)

\begin{tabular}{|l|l|l|l|l|}
\hline \multirow{2}{*}{ Treatment } & Shoot length $(\mathbf{c m})$ & $\begin{array}{l}\text { Root length } \\
(\mathbf{c m})\end{array}$ & $\begin{array}{l}\text { Fresh Weight } \\
(\mathbf{g})\end{array}$ & $\begin{array}{l}\text { Dry Weight } \\
(\mathbf{g})\end{array}$ \\
\cline { 2 - 5 } & Mean \pm SD & Mean \pm SD & Mean \pm SD & Mean \pm SD \\
\hline Control & $28.16 \pm 1.04$ & $21.62 \pm 0.99$ & $7.08 \pm 0.10$ & $3.29 \pm 0.35$ \\
\hline LSBS2 & $36.36 \pm 0.72$ & $31.02 \pm 0.47$ & $12.18 \pm 0.27$ & $5.89 \pm 0.21$ \\
\hline F values & $38.094^{* * *}$ & $218.351^{* * *}$ & $284.554^{* * *}$ & $180.431^{* * *}$ \\
\hline
\end{tabular}

Data are represented by the mean of three replicates \pm standard deviation. Significant difference $*, * *, * * *=$ Extent of Significance LSD (P < 0.05).

Table 3. Chemical characteristic of photosynthetic pigment and total nitrogen content Arachis hypogaea L.

\begin{tabular}{|l|l|l|l|}
\hline Treatment & $\begin{array}{l}\text { Chlorophyll } \\
(\mathbf{m g} \text { g- }\end{array}$ & $\begin{array}{l}\text { Carotenoids } \\
(\mathbf{m g ~ g - 1})\end{array}$ & $\begin{array}{l}\text { Total nitrogen content } \\
(\mathbf{m g} \text { N/g dry plant })\end{array}$ \\
\hline Control & $0.023 \pm 0.003$ & $0.033 \pm 0.002$ & $7.76 \pm 0.35$ \\
\hline LSBS2 & $0.115 \pm 0.001$ & $0.038 \pm 0.001$ & $21.06 \pm 0.64$ \\
\hline F values & $153891.224 * * *$ & $189.458 * * *$ & $1412.282 * * *$ \\
\hline
\end{tabular}

Data are represented by the mean of three replicates \pm standard deviation. Significant difference $*, * *, * * *=$ Extent of Significance LSD $(\mathrm{P}<0.05)$.

Table 4. Biomass accumulation of nodules Arachis hypogaea L. (90 DAI)

\begin{tabular}{|l|l|l|l|}
\hline Treatment & $\begin{array}{l}\text { Nodules number } \\
\text { /plant }\end{array}$ & Nodules fresh weight $(\mathbf{g})$ & Nodules dry weight $(\mathbf{g})$ \\
\hline Control & $23.33 \pm 2.00$ & $0.013 \pm 0.001$ & $0.0018 \pm 0.02$ \\
\hline LSBS2 & $38.00 \pm 2.64$ & $0.17 \pm 0.014$ & $0.004 \pm 0.24$ \\
\hline F values & $163.111^{* * *}$ & $66.239 * * *$ & $25.483^{* * *}$ \\
\hline
\end{tabular}

Data are represented by the mean of three replicates \pm standard deviation. Significant difference $* * *, * * *=$ Extent of Significance LSD $(\mathrm{P}<0.05)$

Table 5. Nitrogenase activity and leghemoglobin content of root nodules

\begin{tabular}{|l|l|c|}
\hline Treatment & $\begin{array}{l}\text { Nitrogenase activity } \\
\left(\mathbf{n} \text {.moles } \mathbf{C}_{\mathbf{2}} \mathbf{H}_{\mathbf{4}} \text { formed / } \mathbf{h} / \mathbf{g} \text { fresh nodules }\right)\end{array}$ & $\begin{array}{l}\text { Leghaemoglobin content } \\
(\mathbf{m g} / \mathbf{g})\end{array}$ \\
\hline Control & $8.62 \pm 1.02$ & $1.2 \pm 0.05$ \\
\hline LSBS2 & $14.80 \pm 0.61$ & $1.4 \pm 0.05$ \\
\hline F values & $167.226^{* * *}$ & $29.500^{* * *}$ \\
\hline
\end{tabular}

Data are represented by the mean of three replicates \pm standard deviation. Significant difference $*, * *, * * *=$ Extent of Significance LSD $(\mathrm{P}<0.05)$

Table 6. Yield parameters of Arachis hypogaea

\begin{tabular}{|l|l|l|l|}
\hline Treatment & Number of pods /plant & Wt. Pods /plant (g) & $\mathbf{1 0 0}$ seed weight (g) \\
\hline Control & $10.33 \pm 0.5$ & $9.46 \pm 0.80$ & $3.10 \pm 0.99$ \\
\hline LSBS2 & $18.67 \pm 0.5$ & $12.57 \pm 0.20$ & $6.33 \pm 0.05$ \\
\hline F values & $90.800^{* * *}$ & $576.032 * * *$ & $149.156 * * *$ \\
\hline
\end{tabular}

Data are represented by the mean of three replicates \pm standard deviation. Significant difference $* * *, * * *=$ Extent of Significance LSD ( $\mathrm{P}<0.05)$. 
Table 7. Nutrients analysis of Arachis hypogaea L seed (90 DAI)

\begin{tabular}{|l|l|l|l|}
\hline Nutrition & Control & LSBS2 & F values \\
\hline Protein $(\%)$ & $13.51 \pm 0.13$ & $17.43 \pm 0.19$ & $3684.295^{* * *}$ \\
\hline Fat (\%) & $42.83 \pm 0.24$ & $46.31 \pm 0.09$ & $1311.886^{* * *}$ \\
\hline Fibre (\%) & $11.2 \pm 0.15$ & $13.73 \pm 0.90$ & $363.573^{* * *}$ \\
\hline Carbohydrate $(\%)$ & $18.64 \pm 0.08$ & $21.50 \pm 0.66$ & $2038.725^{* * *}$ \\
\hline Energy (Kcal) & $555.0 \pm 1.00$ & $563.0 \pm 1.00$ & $173.200^{* * *}$ \\
\hline Calcium (mg/g) & $13.26 \pm 0.20$ & $16.04 \pm 0.10$ & $122.123^{* * *}$ \\
\hline Iron $(\mathrm{mg} / \mathrm{g})$ & $3.64 \pm 0.05$ & $6.36 \pm 0.15$ & $1598.521^{* * *}$ \\
\hline Total oil content (\%) & $38.55 \pm 0.80$ & $49.66 \pm 0.15$ & $1574.386^{* * *}$ \\
\hline
\end{tabular}

Data are represented by the mean of three replicates \pm standard deviation.Significant difference $*, * *, * * *=$ Extent of Significance LSD $(\mathrm{P}<0.05)$.

\subsection{Initial and post-harvest soil characterization}

Soil analysis was done after the experiment with bioinoculant. In the treated soil, a high amount of nitrogen content followed by phosphorus and potassium content was noticed, whereas the control soil recorded low amount of nitrogen phosphorous and potassium. In case of iron, the treated plants recorded in comparison with untreated control plants which recorded. While, other nutrients such as $\mathrm{Mg}, \mathrm{Mn}, \mathrm{Zn}, \mathrm{Na}$ and $\mathrm{Cu}$ recorded significant uptake in treated plants when compared to untreated control plants (Table 8).

Table 8. Physico-chemical analysis of soil experiments (before sowing and post harvesting)

\begin{tabular}{|l|c|c|c|}
\hline Nutrition & Before sowing Soil analysis & \multicolumn{2}{|c|}{ Post harvesting soil analysis } \\
\hline & & Control & 0.53 \\
\hline $\mathrm{EC}(\mathrm{dS} / \mathrm{m})$ & 0.17 & 0.025 & 8.4 \\
\hline $\mathrm{pH}$ & 7.2 & 50 & 61 \\
\hline Nitrogen $(\mathrm{mg} / \mathrm{kg})$ & 50 & 10.5 & 20.6 \\
\hline Phosphorus $(\mathrm{mg} / \mathrm{kg})$ & 10.7 & 120 & 165 \\
\hline Potassium $(\mathrm{mg} / \mathrm{kg})$ & 118 & 2.3 & 3.97 \\
\hline Magnesium $(\mathrm{mg} / \mathrm{kg})$ & 2.5 & 9.5 & 10.67 \\
\hline Sulphur $(\mathrm{mg} / \mathrm{kg})$ & 9.2 & 5.1 & 0.321 \\
\hline Calcium $(\mathrm{mg} / \mathrm{kg})$ & 5.1 & 0.09 & 4.78 \\
\hline Zinc $(\mathrm{ppm})$ & 0.09 & 1.34 & 0.52 \\
\hline Iron $(\mathrm{ppm})$ & 1.37 & 0.43 & 3.52 \\
\hline Manganese $(\mathrm{ppm})$ & 0.43 & 1.78 & 3.2 \\
\hline Sodium $(\mathrm{mg} / \mathrm{kg})$ & 1.78 & 1.40 & \\
\hline Cupper $(\mathrm{ppm})$ & 1.42 & & \\
\hline
\end{tabular}

\section{DISCUSSION}

Plant growth promoting beneficial characters are produced by various groups of microorganisms belonging to bacteria [17] actinomycetes and fungi [18]. These rhizosphere organisms are soil inhabitant, non-pathogenic capable of triggering plant immunity towards resistance against various pests and pathogens as well as plant growth promotion. Considering their ability in the crop improvement, they are used as a substitute for chemical application in agriculture. Most of the rhizosphere bacteria secrete secondary metabolites called siderophores which acts as chelating agents for ferric iron, produced under low iron stress [19].

In the present study, a bacterium (LSBS2) was isolated from the agricultural soil, on the basis of biochemical and 16s rRNA gene the isolated bacterium was identified as Bacillus subtilis. In the past, various reports are documented for the isolation of B.subtilis from rhizosphere soil from India by biochemical and molecular characterization [20]. As a next step, the qualitative assessment of siderophores production was demonstrated from the isolated B.subtilis (LSBS2) under nutrient agar medium with iron limiting stress. In earlier reports B.subtilis are able to produce higher yields of siderophores under iron stress conditions [21]. In the current investigation, the siderophore was positive isolated using the CAS reagent which revealed change in blue to orange colour which resemblance similar observations of siderophore production [22]. [23] reported that different doses of zinc and magnesium also play a major role in the induction of siderophore production by the formation of yellow green fluorescent pigment around them on Nutrient agar medium.

In order to detect the type of siderophore, we have used tetrazolium test for the estimation of siderophore type using spectrophotometric assay, the subjected extract showed appearance of red colour indicating the presence of catacholate type of siderophores. This result is well supported by previous findings [24]in which the authors described 
the ability of siderosphore producing Bacillus with biocontrol potential.

It was noticed that a clear red spots was developed on the TLC plates revealed the positive response of catacholate type siderophores in the test extract. In a same manner, the detection of siderophores was confirmed in the bacillus culture supernant obtained from rhizosphere soil [25]. The partial purification of siderophore resulted a yield of $20 \mathrm{mg} \mathrm{lit}^{-1}$. Further, FTIR spectrum of LSBS2 shows the adsorption bands at 3445, 2951, 1652, 1455 and $1143 \mathrm{~cm}^{1}$ respectively, which indicates the presence of $(-\mathrm{OH})$, aromatic $(-\mathrm{CH}),(-\mathrm{C}=\mathrm{O}),\left(-\mathrm{CH}_{2}\right)$ and $(\mathrm{C}-\mathrm{O}-\mathrm{C})$ linkage. These functional groups are present in catecholate type of siderophore. So that the purification of siderophore production in FTIR analysis conformed to catecholate type are present in LSBS2 that are specific to compound 2,3 dihydroxybenzoic acid [26]. In HPLC analysis the peaks appeared at retention time $1.621 \mathrm{~min}, 2.188 \mathrm{~min}$, $2.473 \mathrm{~min}$. The peaks appeared at 1-0.767 min, 2$2.033 \mathrm{~min}$, using was used as a standard. From these results it is clearly reveals that the presence of purified 2-3 dihydroxy benzoic acid siderophore in the sample $[27,28]$. Microbial siderophores directly enhances the availability of iron present in the rhizosphere soil, thereby stimulates plant growth and suppress the growth of the phytopathogens by supplying low iron [29]. In addition to the plant growth promotion, [30] described the role of siderophores in inducing systemic resistance against pathogen attack through upregulation of defence responses JA and ET genes.

Furthermore, the field experiment was conducted with peanut to assess the bioinoculant efficacy of siderophore producing LSBS2 isolate on plant growth and other physic-chemical parameters. In the present study, there was a remarkable enhancement of various plant growth parameters namely, plant biomass, pigment content, Iron and oil content in the bioinoculant-treated Arachis plants in comparison with the control plants. In the past decades, several investigation on the application of different species of Pseudomonas provided evidence of siderophores directly involved in the stimulation of plant growth and also protects the plants against various biotic stresses [31]. The siderophores producing bioinocultant treated to mung bean plants protect the plant by reducing the chlorotic lesions on the leaves and also increased the chlorophyll levels under iron-deficient stress [32]. Likewise, increase carotenoids level was observed in siderophores producing strain (Ros2) treated to wheat plants in the presence of pesticide stress [33]. [34] isolated a potential siderophores producing organism from rhizosphere, this bacterium treated to peanut plants showed drastic increase in the seed germination, shoot, root length and also recoded enhanced levels of chlorophyll. Furthermore in this study, the $\mathrm{pH}$ and Electrical conductivity, NPK and iron content in the soil is influence by the presence of siderophores secreting microorganisms, this is in agreement with the results obtained by [35]. The present findings also provide evidence of enhanced oil content, chlorophyll, carotenoids pigments and micro and macronutrients in siderophore producing bioinoculant-treated peanut plants. These enhanced beneficial characters are correlated with the previous studies [36], where the authors demonstrated that siderophores producing soil microorganisms advances various mineral dissolution to soluble phases that are absorbed by the plants, thereby increases the plant biomass and mobilizes the uptake of nutrient. In an independent study, [37] noticed significant increase in the rice grain oil content after application of sideropshores producing rhizobacteria.

\section{CONCLUSIONS}

The results from the present investigation provided evidence of positive correlation between the production of siderophores and plant growth and nutrient uptake; in addition we have also noticed increase in the iron and oil content. Taken together, the present result suggested that the occurrence of bacillibactin type siderophores in the isolate LSBS2 play a key role in iron chelation that stimulates the overall Arachis hypogaea plant immunity

\section{REFERENCES}

[1] R.Z. Sayyed, N. Ilyas, B. Tabassum, A.Hashem, E.F.Abd Allah, H.P. Jadhav, Role of Plant Growth-Promoting Rhizobacteria in Future Climatic Scenario, Environ. Biotech. Sustainable Future., pp.175-189, 2019.

[2] M. Saha, S. Sarkar, B. Sarkar, B.K. Sharma, S. Bhattacharjee, T. Tribedi, 'Microbial siderophores and their potential applications a review,' Environ. Sci. Pollut. Res., vol. 23, no.5, pp.3984-3999, 2016.

[3] S.M. Dalvi, R.R. Rakh, 'Siderophore producing Pseudomonas cf. monteilii 9 for assured biological control of Sclerotium rolfsii causing stem rot of groundnut,' Bio sci Discov., vol.8, no.3,pp.546$555,2017$.

[4] M.A.B. Mia, Z.H. Shamsuddin, Z. Wahab, 'Highyielding and quality banana production through plant growth-promoting rhizobacterial (PGPR) inoculation, 'Fruits., vol. 60, no.3, pp.179-185, 2005.

[5] K.N. Raymond, E.A. Dertz, S.S Kim, 'Enterobactin: an archetype for microbial iron transport,' Proc. Nat. Acad. Sci. U.S.A. 100,2003.

[6] Pravin Vejan, Rosazlin Abdullah, Tumirah Khadiran, Salmah Ismail, and Amru Nasrulhaq Boyce. 'Role of Plant Growth Promoting Rhizobacteria in Agricultural Sustainability-A Review,'.Molecules., vol.21, no. 5, pp.573, 2016.

[7] Xianmei, Yu, Chengxiang, Li, Xin, Guangfang Zhou. 'The siderophore-producing bacterium, Bacillus subtilis CAS15, has a biocontrol effect on Fusarium wilt and promotes the growth of 
pepper,'European J Soil Bio.,vol. 47, pp.138$145,2011$.

[8] J.G. Cappuccino, and N. Sherman, 'Microbiology; a laboratory manual ( $8^{\text {th }}$ edition),' $p u b$.,Pearson, vol. $13,978,2002$.

[9] A.N. Babu, S. Jogaiah, Ito, K.A. Amruthesh, L.Tran, 'Improvement of growth, fruit weight and early blight disease protection of tomato plants by rhizosphere bacteria is correlated with their beneficial traits and induced biosynthesis of antioxidant peroxidase and polyphenol oxidase,' Plant Sci., vol. 231,pp. 62-73,2015.

[10] D.B. Alexander, D.A. Zubere, 'Use of Chromazurol Sulphonate reagents to evalu-ate siderophore production by rhizosphere bacteria,' Biol. Fertil. Soils., Vol. 12, pp.39-45,1999.

[11] B.E. Clark, R.Storey, J. Mohseni, R.N. Little, Chakraborty, 'Characterization of a catechol-type siderphore and the detection of an outer membrane receptor protein from Rhizobium leguminosarum RL 312,' American Society for Microbiology., 2003.

[12] R.W.E. Hardy, R.W. Holstein, E.K. Jackson, R.S. Burns, 'The acetylene ethylene assay for nitrogen fixation, Laboratory and field evaluation,' Plant physiol., vol. 43, pp.1185-1207,1968.

[13]D.O. Wilson, and H.M. Reisenauer, 'Cobalt requirement of symbiotically grown Alfalfa, 'Plant soil., Vol. 19, pp.364 - 373,1963.

[14] O.I. Arnon, 'Copper enzymes in isolated chloroplasts.1. Polyphenol Oxidase in Betavulgaris,' Plant physical., Vol. 24, pp.115,1949 .

[15] J.T.O. Kirk, and R.L. Allen, 'Dependence of chloroplast pigments synthesis on protein synthetic Selenium dioxide were powdered separately and mixed together effects on actilione,' Bioche. Biophy. Research J. Canada., vol.27, pp.523-530, 1965.

[16] O.I. Arnon, 'Copper enzymes in isolated chloroplasts.1. Polyphenol Oxidase in Betavulgaris,' Plant physical. Vol. 24, pp.1-15, 1949

[17] A.N. Babu, S. Jogaiah, Ito, K.A. Amruthesh, L.Tran, 'Improvement of growth, fruit weight and early blight disease protection of tomato plants by rhizosphere bacteria is correlated with their beneficial traits and induced biosynthesis of antioxidant peroxidase and polyphenol oxidase,' Plant Sci., vol. 231,pp. 62-73,2015.

[18] S. Jogaiah, M. Abdelrahman, L-S.P.Tran, Ito, 'Different mechanisms of Trichoderma virensmediated resistance in tomato against Fusarium wilt involve the jasmonic and salicylic acid pathways,' Mol. Plant Path. vol. 19, pp. 870$882,2018$.

[19] S,Sasirekha, S.Srividya, 'Siderophore production by Pseudomonas aeruginosa FP6, a biocontrol strain for Rhizoctonia solani and Colletotrichum gloeosporioides causing diseases in chilli,' Agriculture and Nat. Resources., Vol.50, pp.255256,2016.

[20] S,Sasirekha, S.Srividya, 'Siderophore production by Pseudomonas aeruginosa FP6, a biocontrol strain for Rhizoctonia solani and Colletotrichum gloeosporioides causing diseases in chilli,'
Agriculture and Nat. Resources., Vol.50, pp.255256,2016.

[21] R.Z.Sayyed, M.D. Badgujar, H.M.Sonawane, M,M. Mhaske, S.B. Chincholkar, 'Production of microbial iron chelators (siderophores) by fluorescent pseudomonas,' Indian J biotechnol., Vol.4, pp.484-490,2005.

[22] A. Pahari, T.K. Dangar, B.B. Mishra, 'Siderophore quantification of bacteria from sundarban and its effect on growth of brinjal (Solanum melongena L.),' The Bioscan., Vol. 11, pp.2147-2151,2016.

[23] I. Mehri, A. Khessairi, T. Yousra, S. Neila, D. Imen, M.J. Marie, H. Abdennasseur, 'Effect of dose response of zinc and manganese on siderophores induction,' American J. Environ. Sci., vol. 8, pp.143-055,2012.

[24] Santos-Villalobos, 'Burkholderia cepacia XXVI siderophore with biocontrol capacity against Colletotrichum gloeosporioides,' World J. Microbiol. Biotech., Vol.28,pp.2615-23,2012.

[25] K. Kavitha, A.Suganya, K. Umaa Rani, B. Ramesh, B, 'Screening and Partial Purification of Hydroxamate Type Siderophore from Pseudomonas sp,' Int. J. Curr. Microbiol. App. Sci., vol. 6, pp.2380-2385, 2017.

[26] H. Siebner-Freibach, S. Yariv, Y. Lapides, Y. Hadar, Y. Chen, 'Thermo-FTIR spectroscopic study of the siderophore ferrioxamine B: spectral analysis and stereochemical implications of iron chelation, pH, and temperature,' J. Agri. Food Chem., Vol.53, pp.3434-3443,2005.

[27] E. Storey, 'Characterization of a DihydroxamateType Siderophore Produce by Rhizobium leguminosarum IARI 917,' East Tennessee State University, Johnson City, TN. 2005.

[28] H. Bruns, M. Crüsemann, A.C. Letzel, M. Alanjary, J.O. McInerney, P.R.Jensen, S. Schulz, B.S. Moore, N. Ziemert, 'Function-related replacement of bacterial siderophore pathways' The ISME Journal. vol. 12, pp.320-329,2019.

[29] B.Joseph, R.R.Patra, R. Lawrence, 'Characterization of plant growth promoting rhizobacteria associated with chickpea (Cier arietinum L.),' Int. J. Plant Prod. Vol.2, pp.141$152,2007$.

[30] P.A.H.M. Bakker, L.X. Ran, C.M.J. Pieterse, L.C.Van Loon, 'Understanding the involvement of induced systemic resistance in rhizobacteriamediated biocontrol of plant diseases,' Can. J. Plant Pathol., vol. 25, pp.5-9, 2003.

[31] E. Gamalero, B.R. Glick, 'Mechanisms used by plant growth-promoting bacteria. In: Maheshwari DK, editor. Bacteria in Agrobiology: Plant Nutrient Management. Berlin, Heidelberg, Germany.' Springer Verlag., pp.17-46,2011.

[32] A. Sharma, B.N. Johri, A.K. Sharma, B.R. Glick, 'Plant growth-promoting bacterium Pseudomonas sp. strain GRP3 influences iron acquisition in mung bean (Vigna radiata L. Wilzeck),' Soil Biol. Biochem., Vol. 38, pp.887-894, 2003.

[33] I. Munir, A. Bano, M. Faisal, 'Impact of phosphate solubilizing bacteria on wheat (Triticum aestivum) in the presence of pesticides,'Braz.J.Biol.,Vol.79, doi.org/10.1590/151 9-6984.172213,2019.

[34] R.Z. Sayyed, N.S. Gangurde, P.R. Patel, S.A.Joshi, S.B. Chincholkar, 'Siderophore production by 
Alcaligenes faecalis and its application for growth promotion in Arachis hypogaea,' Indian $J$ Biotechnol., vol.9, pp.302-307,2010.

[35] V. Kumar, S. Menon, H. Agarwal, D. Gopalakrishnan, 'Characterization and optimization of bacterium isolated from soil samples for the production of siderophores,' Resource-efficienttechnol.vol.3,pp.434-439,2017.

[36] M. Shirvani, F. Nourbakhsh, 'Desferrioxamine-B adsorption to and iron dissolution from palygorskite and sepiolite,' Appl Clay Sci., vol. 48, pp.393-397, 2010.

[37] A.Sharma, D. Shankhdhar, S.C. Shankhdhar, 'Enhancing grain iron content of rice by the application of plant growth promoting Rhizobacteria,' Plant Soil Environ., Vol. 59, pp.89-94,2013. 